\title{
SIRT3 Regulates Mitochondrial Protein Acetylation and Intermediary Metabolism
}

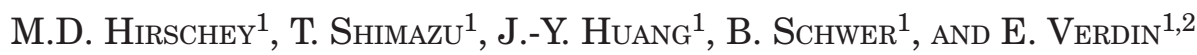 \\ ${ }^{1}$ Gladstone Institute of Virology and Immunology, San Francisco, California 94158 \\ ${ }^{2}$ Department of Medicine, University of California, San Francisco, California 94143 \\ Correspondence: everdin@gladstone.ucsf.edu
}

\begin{abstract}
The sirtuins are a family of nicotinamide adenine dinucleotide $\left(\mathrm{NAD}^{+}\right)$-dependent protein deacetylases that regulate cell survival, metabolism, and longevity. Humans have seven sirtuins (SIRT1-SIRT7) with distinct subcellular locations and functions. SIRT3 is localized to the mitochondrial matrix and its expression is selectively activated during fasting and calorie restriction. Activated SIRT3 deacetylates several key metabolic enzymes-acetyl-coenzyme A synthetase, long-chain acylcoenzyme A (acyl-CoA) dehydrogenase (LCAD), and 3-hydroxy-3-methylglutaryl CoA synthase 2 - and enhances their enzymatic activity. Disruption of SIRT3 activity in mice, either by genetic ablation or during high-fat feeding, is associated with accelerated development of metabolic abnormalities similar to the metabolic syndrome in humans. SIRT3 is therefore emerging as a metabolic sensor that responds to change in the energy status of the cell and modulates the activity of key metabolic enzymes via protein deacetylation.
\end{abstract}

Proper mitochondrial function requires careful regulation of the activity of multiple metabolic enzymes and is in turn required for metabolic homeostasis. Changes in mitochondrial number and activity are implicated in aging, cancer, and other diseases (Wallace 2005). Mitochondrial dysfunction appears to play a particularly important role in the pathogenesis of the metabolic syndrome - a group of metabolic abnormalities characterized by central obesity, dyslipidemia, high blood pressure, and increased fasting glucose. A number of abnormalities in mitochondria have been identified in patients and animal models with the metabolic syndrome, including reduced mitochondrial mass (Kelley et al. 2002), altered mitochondrial morphology (Civitarese et al. 2010), reduced fatty-acid oxidation (Zhang et al. 2007), lower oxidative phosphorylation (Petersen et al. 2005; Befroy et al. 2007), and increased reactive oxygen species (ROS) (Patti et al. 2003; Petersen et al. 2004; Civitarese et al. 2006; Ukropcova et al. 2007). Various posttranslational modifications fine-tune the activities of metabolic enzymes, and acetylation is increasingly recognized as an important posttranslational modification for a number of key metabolic pathways. A large number of metabolic enzymes are acetylated in a variety of organisms (Wang et al. 2010; Zhao et al. 2010). This chapter focuses on the role of the major mitochondrial protein deacetylase, SIRT3, its regulation during fasting, calorie restriction and high-fat feeding, the identification and characterization of its targets, and its role in the pathogenesis of the metabolic syndrome.

\section{ACETYLATION IS A PREVALENT MITOCHONDRIAL PROTEIN POSTTRANSLATIONAL MODIFICATION}

Lysine acetylation is a reversible and highly regulated posttranslational modification. It was initially discovered on histones, but several nonhistone proteins have since been identified to be lysine acetylated (Glozak et al. 2005). Acetylation takes place on the $\varepsilon$-amino group of lysine residues and regulates diverse protein properties, including DNA - protein interactions, subcellular localization, transcriptional activity, protein stability, proteinprotein interactions, and last, but not least, enzymatic activity. Lysine acetylation is under the control of competing enzymes, commonly called histone acetyltransferases (HATs) and histone deacetylases, although several of these enzymes mainly target nonhistone proteins.

Although acetylation was originally thought to affect only histones, an extensive proteomic survey of cellular proteins revealed that a large number of mitochondrial proteins are subject to reversible lysine acetylation (Kim et al. 2006). In this study, mouse liver mitochondria were purified, subjected to proteolytic digestion, and the resulting lysate subjected to immuno-affinity purification of lysine-acetylated peptides. Nano-high-performance liquid chromatography/tandem mass spectrometry (HPLC/ MS/MS) analysis of the acetylated peptides identified 277 lysine acetylation sites in 133 mitochondrial proteins, thereby conclusively establishing that lysine acetylation is an abundant posttranslational modification in the 
mitochondrion. Interestingly, mitochondrial protein acetylation appeared to be linked to metabolic status because $62 \%$ of acetylated proteins were identified in mitochondrial fractions isolated from both fed and fasted animals, $14 \%$ were specific to fed mice, and $24 \%$ were specific to fasted mice. Most lysine-acetylated proteins from mitochondrial fractions were metabolic enzymes (91 proteins). Interestingly, ATP synthase $F_{o}$ subunit 8 , one of 15 proteins encoded by mitochondrial DNA, was also acetylated, implying that the acetylation reaction can occur de novo within mitochondria.

These early results suggested that as much as $20 \%$ of all mitochondrial proteins are lysine acetylated (Kim et al. 2006). However, more recent proteomic analyses of lysine-acetylated mitochondrial proteins showed that as much as $50 \%$ of all mitochondrial proteins are acetylated, and that proteins involved in energy metabolism are overrepresented. This includes proteins in the tricarboxylic acid (TCA) cycle, oxidative phosphorylation, $\beta$-oxidation of lipids, amino acid metabolism, carbohydrate metabolism, nucleotide metabolism, and the urea cycle (Wang et al. 2010; Zhao et al. 2010). Transporter and channel proteins are also lysine acetylated. Interestingly, $44 \%$ of mitochondrial dehydrogenases are acetylated. Among them, 14 use $\mathrm{NAD}^{+}$as the electron acceptor to catalyze biochemical reactions in oxidative, catabolic routes.

\section{SIRTUINS ARE NAD ${ }^{+}$-DEPENDENT PROTEIN DEACETYLASES}

SIRT3 belongs to a larger family, the sirtuins, that have important roles in controlling metabolism in a variety of organisms (for review, see Schwer and Verdin 2008). Named after the yeast silent information regulator 2 (Sir2), sirtuins regulate important biological pathways in eubacteria, archaea, and eukaryotes. Yeast Sir2 and some sirtuins are protein deacetylases (Imai et al. 2000; Landry et al. 2000; Smith et al. 2000). Sirtuins mediate a deacetylation reaction that couples lysine deacetylation to $\mathrm{NAD}^{+}$hydrolysis. This hydrolysis yields $O$ acetyl-ADP-ribose, the deacetylated substrate, and nicotinamide (for review, see Denu 2005; Sauve et al. 2006).

Bacteria and archaea encode one or two sirtuins, but mice and humans possess seven sirtuins (SIRT1-7). Mouse and human sirtuins occupy different subcellular compartments, such as the nucleus (SIRT1, -2, -3, -6, and -7), cytoplasm (SIRT1 and -2), and mitochondria (SIRT3, -4, and -5) (Blander and Guarente 2004; North and Verdin 2004; Michishita et al. 2005; Chen et al. 2006; Haigis et al. 2006; Tanno et al. 2006). The sirtuins are assigned to five subclasses (I-IV and U) based on the phylogenetic conservation of a core domain of approximately 250 amino acids (Frye 1999, 2000). Among mammalian sirtuins, SIRT1, -2 , and -3 are closely related class I sirtuins, show high homology to the yeast sirtuins Sir2, Hst1, and Hst2, and exhibit robust deacetylase activity. Class II sirtuins (SIRT4) have no detectable deacetylase activity and instead show weak ADP-ribosyltransferase activity (Haigis et al. 2006; Ahuja et al. 2007). Class
III sirtuins (SIRT5) have only weak deacetylase activity on histone substrates (Verdin et al. 2004; Nakagawa et al. 2009); class IV sirtuins have ADP ribosyltransferase and deacetylase activity (SIRT6) or unknown activity (SIRT7; Kawahara et al. 2009; Haigis and Sinclair 2010). Class U sirtuins are intermediate between classes I and IV and have only been observed in bacteria.

The dependence of sirtuins on $\mathrm{NAD}^{+}$suggests that their enzymatic activity is directly linked to the energy status of the cell via the cellular $\mathrm{NAD}^{+}: \mathrm{NADH}$ ratio; the absolute levels of $\mathrm{NAD}^{+}, \mathrm{NADH}$, or nicotinamide; or a combination of these variables (Lin et al. 2000, 2002, 2004; Bitterman et al. 2002; Anderson et al. 2003).

\section{SIRT3 IS A MITOCHONDRIAL DEACETYLASE}

Three sirtuins, SIRT3, SIRT4, and SIRT5, are located in mitochondria (Onyango et al. 2002; Schwer et al. 2002; Michishita et al. 2005; Haigis et al. 2006), and endogenous SIRT3 is a soluble protein in the mitochondrial matrix (Schwer et al. 2002, 2006). Interestingly, SIRT3 is translated in the cytoplasm as a longer, enzymatically inactive precursor that is imported into the mitochondrion. Following import, the first 100 amino acids of SIRT3 are proteolytically cleaved, leading to a final enzymatically active SIRT3 with a molecular mass of $28 \mathrm{kDa}$ (Fig. 1).

Initial controversies regarding the subcellular localization of SIRT3 have been resolved. For example, a small fraction of full-length, unprocessed human SIRT3 was also reported to be localized to the nucleus. Recent results from the Reinberg laboratory indicate that this nuclear form of SIRT3 interacts with specific genes (Scher et al. 2007; Reinberg 2011). Another question centered on whether SIRT3 is a primary mitochondrial protein in mice. This controversy was linked to the finding that mouse SIRT3 cDNA lacked the amino-terminal mitochondrial targeting domain identified in the human protein. However, we used an antiserum for SIRT3 to confirm that mouse endogenous SIRT3 is exclusively mitochondrial: We could not detect any nuclear SIRT3 (Lombard et al. 2007), and a recently identified mouse SIRT3 cDNA encodes a protein that is imported to the mitochondrial matrix, like human SIRT3 (Cooper et al. 2009; Jin et al. 2009).

Most importantly, the identification of a protein deacetylase within the mitochondrial matrix suggested that mitochondrial proteins were acetylated and that SIRT3 might regulate their acetylation level and their biological activities.

In support of this model, mitochondrial proteins were strikingly hyperacetylated in mice lacking SIRT3 (SIRT3KO mice) (Lombard et al. 2007). In contrast, mice lacking either SIRT4 or SIRT5 showed no obvious change in mitochondrial protein acetylation (Lombard et al. 2007). These observations supported the model that SIRT3 is the major mitochondrial deacetylase. However, despite this striking biochemical abnormality, SIRT3KO mice were healthy under normal laboratory conditions and conditions of mild stress, such as short- 


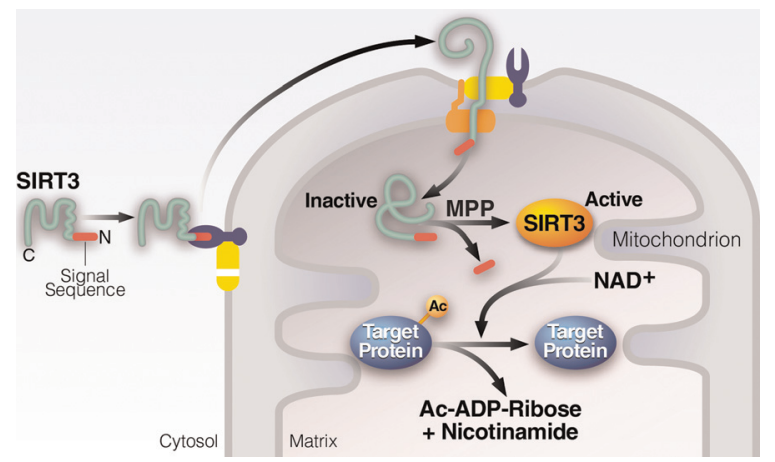

Figure 1. SIRT3 is a mitochondrial $\mathrm{NAD}^{+}$-dependent protein deacetylase. SIRT3 is encoded in the nucleus and imported into the mitochondrial matrix by a canonical mitochondrial targeting sequence. After import, a mitochondrial protein peptidase cleaves the targeting sequence and activates the deacetylase SIRT3 into its active form. Using $\mathrm{NAD}^{+}$as a cofactor, SIRT3 removes acetyl groups from protein lysine residues within mitochondrial proteins and generates $O$-acetyl-ADP ribose and nicotinamide.

term food deprivation, and showed normal overall metabolism and cold resistance.

\section{SIRT3 DEACETYLATES MULTIPLE MITOCHONDRIAL PROTEINS DURING FASTING}

Because SIRT3KO mice had no overt phenotype under basal conditions, we tested various stress conditions where SIRT3 could play a possible role. In wild-type (WT) mice, SIRT3 protein and mRNA expression is up-regulated during fasting, a clue that SIRT3 might be involved in the fasting response. The fasting response in mammals is characterized by dramatic changes in metabolic fluxes. Fatty acids are released from triglycerides in white adipose tissue and transported to the liver where they become oxidized. In contrast to other tissues, hepatic fatty-acid oxidation is incomplete and does not progress much beyond acetyl-coenzyme A (acetyl-CoA). The accumulating acetyl-CoA is used as a substrate for the generation of ketone bodies and acetate. Both acetate and ketone bodies diffuse within the organism and are used by peripheral tissues as energy sources.

Metabolomic analysis of livers from SIRT3KO mice revealed multiple abnormalities in lipid metabolism, including increased triglycerides and accumulation of acylcarnitines, which are intermediate products of mitochondrial fatty-acid oxidation. Histological examination of liver tissue from SIRT3KO mice revealed hepatic steatosis. These data suggested that SIRT3KO mice have a defect in fatty-acid oxidation. Measurement of palmitate oxidation in liver extracts from WT and SIRT3KO mice revealed a primary defect in $\beta$-oxidation in the absence of SIRT3.

To identify SIRT3 targets, we purified mitochondria from SIRT3KO mice, digested mitochondrial matrix lysates with trypsin, immunoprecipitated the acetylated peptides with an antiacetyllysine antibody, and processed the immunoprecipitated peptide for mass spectrometry analysis. This analysis identified more than 1000 acetylated peptides (Fig. 2) (DB Lombard, unpubl.). Multiple enzymes in the mitochondrial $\beta$-oxidation pathway were found to be acetylated in mice lacking SIRT3, including carnitine $O$-palmitoyltransferase 1 and 2, carnitine/acetylcarnitine translocase, acyl-CoA dehydrogenase (very long, long, medium, and short chain), enoyl-CoA hydratase, hydroxyacyl-CoA dehydrogenase, and 3-ketoacylCoA thiolase. Because the metabolomic data indicated a selective accumulation of acylcarnitines with a chain length greater than 16 , we focused our analysis on longchain acyl-CoA dehydrogenase (LCAD) as a critical enzyme targeted by SIRT3. We identified a single lysine (K42) in LCAD whose acetylation was regulated by SIRT3. The acetylated enzyme was inhibited and its deacetylation by SIRT3 enhanced its activity in vitro and in vivo.

Mice lacking SIRT3 exhibited other hallmarks of fattyacid oxidation disorders: reduced ATP levels and intolerance to cold exposure, particularly during fasting (Fig. 3) (Hirschey et al. 2010).

In a parallel study, we found that another key enzyme of the fasting response, 3-hydroxy,3-methylglutaryl-CoA synthase (HMGCS2), is also regulated by SIRT3. HGMCS2 catalyzes the rate-limiting step in ketone body synthesis (Fig. 3). During fasting, SIRT3 deacetylates three lysine residues on HMGCS2, inducing an increase in its enzymatic activity and ketone body production. Using molecular dynamics simulation modeling,

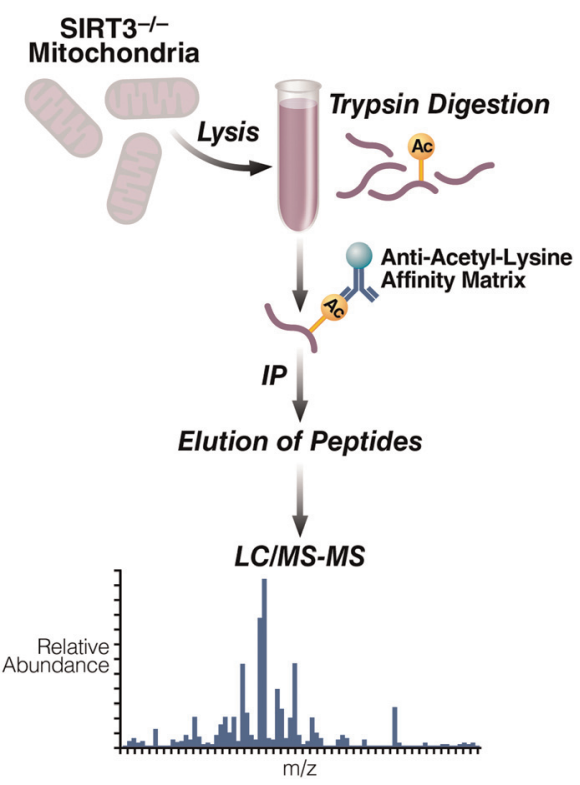

Figure 2. Identification of acetylated mitochondrial proteins from mouse tissue. Mitochondria are purified from mouse tissue lacking SIRT3, lysed, and subjected to trypsin protein digestion. Acetylated peptides are enriched using an antiacetyllysine affinity matrix, eluted with dilute acid, and analyzed by liquid chromatography/tandem mass spectrometry (LC/MS-MS). 


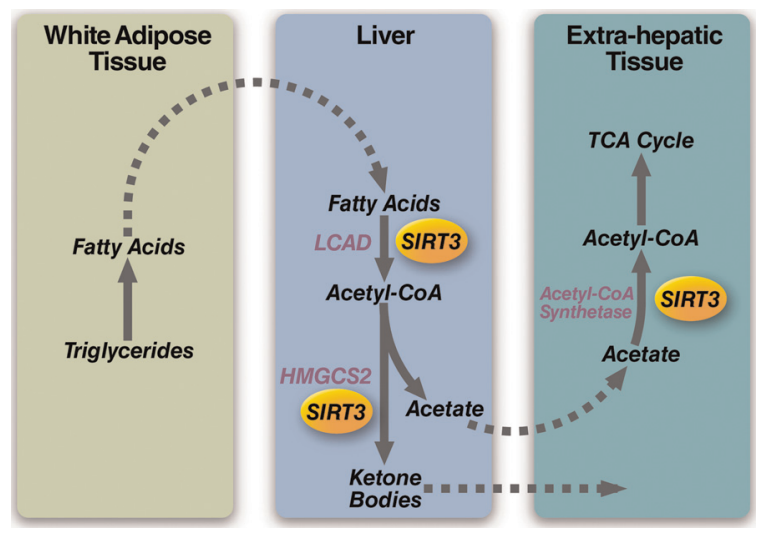

Figure 3. SIRT3 regulates metabolism during fasting. During metabolic stress, such as fasting, lipids are liberated from storage in adipose tissues, transported through the blood bound to albumin, and imported into the liver for oxidation and ATP production. SIRT3 is up-regulated in response to fasting in the liver and deacetylates several mitochondrial proteins, including long-chain acyl-CoA dehydrogenase (LCAD) and 3-hydroxy,3methyl-glutaryl-CoA synthase 2 (HMGCS2), increasing their enzymatic activity. By-products of lipid oxidation such as acetate and the ketone body $\beta$-hydroxybutyrate are exported from the liver and used for energy production in extrahepatic tissues. SIRT3 also deacetylates acetyl-CoA synthetase 2 (AceCS2) in extrahepatic tissues to generate acetyl-CoA from acetate, which can be consumed in the TCA cycle.

we found that deacetylation of these three lysine residues changed the conformation of the catalytic pocket and positioned key catalytic residues nearby the substrate acetyl-CoA. Finally, mice lacking SIRT3 showed decreased ketone body levels during fasting, highlighting another role of SIRT3 in the fasting response (Fig. 3) (Shimazu et al. 2010).

Under ketogenic conditions, such as fasting, the liver of mammals releases substantial amounts of acetate into the bloodstream (Seufert et al. 1974; Buckley and Williamson 1977; Yamashita et al. 2001), at least in part via the activation of an acetyl-CoA hydrolase (Matsunaga et al. 1985). The released acetate freely diffuses to peripheral tissues but must be activated before it can be utilized for metabolism (Fig. 3). The cytoplasmic (AceCS1) and mitochondrial (AceCS2) acetyl-CoA synthases activate acetate and are differentially regulated: Fasting induces mitochondrial AceCS2 expression (Fujino et al. 2001) and decreases cytoplasmic AceCS1 expression in the liver and other tissues (Fujino et al. 2001; Sone et al. 2002). These observations point to an interesting model. Under fasting and ketogenic conditions, acetate could be released from the liver and utilized by AceCS2 to generate acetyl-CoA in extrahepatic tissues (Fujino et al. 2001).

AceCS2 was identified by our group and John Denu's group as the first acetylated target of SIRT3 (Hallows et al. 2006; Schwer et al. 2006). In the prokaryote Salmonella enterica, a sirtuin called CobB deacetylates acetyl-CoA synthetase, activates its enzymatic activity, and allows the bacteria to grow on acetate as a carbon source (Starai et al. 2002). Remarkably, the site of acetylation in $S$. enterica acetyl-CoA synthase is highly conserved throughout evolution, including the lysine that becomes acetylated. Similar to what is observed in S. enterica, SIRT3 deacetylates AceCS2 and activates the enzyme (Schwer et al. 2006). Denu and colleagues made the same observation and further showed that the cytoplasmic acetyl-CoA synthase, AceCS1, which is involved in lipid synthesis, is regulated in a similar manner, but the deacetylase in this case is SIRT1 (Hallows et al. 2006). Recent experiments indicate that activation of acetate by AceCS2 has a specific and unique role in thermogenesis during fasting. Mice lacking AceCS2 (AceCS2KO) show 50\% decreased muscle ATP levels during fasting in comparison to WT (Sakakibara et al. 2009). Fasted AceCS $2 \mathrm{KO}$ mice become significantly hypothermic and exhibit reduced exercise capacity. These findings demonstrate that activation of acetate by AceCS2 is pivotal in thermogenesis, especially under low-glucose or ketogenic conditions, and is crucially required for survival. Interestingly, the phenotypes of mice lacking SIRT3 or AceCS2 overlap significantly because mice lacking SIRT3 also show defective thermogenesis and significant mortality when fasted in the cold (Hirschey et al. 2010).

Because a large number of mitochondrial proteins are subject to reversible lysine acetylation (Kim et al. 2006), several other SIRT3 substrates likely exist. For example, mice lacking SIRT3 have reduced ATP production $(>50 \%)$, several components of complex I of the electron transport chain are hyperacetylated, and complex I activity is inhibited (Ahn et al. 2008). Furthermore, glutamate dehydrogenase and isocitrate dehydrogenase 2 were also identified as targets of SIRT3 (Schlicker et al. 2008).

These studies showed that SIRT3 regulates energy homeostasis during nutrient deprivation. It controls fattyacid catabolism (Hirschey et al. 2010), ketone body synthesis (Shimazu et al. 2010), and acetate metabolism (Hallows et al. 2006; Schwer et al. 2006), crucial metabolic pathways that are activated during fasting.

\section{SIRT3 ACTIVITY IS INDUCED DURING CALORIE RESTRICTION}

Calorie restriction (CR) is a low-calorie dietary regimen without malnutrition. It extends the life span of yeast, worms, flies, and mammals and decreases the incidence of age-associated disorders, such as cardiovascular disease, diabetes, and cancer in animal models (Bordone and Guarente 2005; Masoro 2005). In rodents, a 20\%$40 \%$ reduction of calorie intake extends life span by up to $50 \%$ (McCay et al. 1935). Whereas the positive effects of CR in mammals are well studied, the molecular mechanism of CR is not fully understood (Koubova and Guarente 2003).

Mitochondrial protein acetylation levels change in a tissue-specific manner during calorie restriction in mice. The acetylation level of more proteins increases in the liver, whereas the opposite is observed in brown adipose 
tissue (Schwer et al. 2009). These observations suggest that changes in mitochondrial protein acetylation could represent an important signal during CR. SIRT3 is implicated in metabolic regulation during CR because both fatty-acid oxidation and ketone body production increase during CR (Shi et al. 2005). Importantly, fasting and CR are not equivalent and induce only partially overlapping physiological responses. For example, acute starvation increases the $\mathrm{NAD}^{+}: \mathrm{NADH}$ ratio in liver, but $\mathrm{CR}$ decreases this ratio (Hagopian et al. 2003a,b).

Interestingly, SIRT3 expression is activated in brown adipose tissue by $\mathrm{CR}$ and by exposure to cold (Shi et al. 2005). SIRT3 is also essential for CR-mediated reduction in oxidative stress. In the absence of SIRT3, the reduction in oxidative stress normally observed during $\mathrm{CR}$ is lost (Qiu et al. 2010; Someya et al. 2010). Two distinct enzymes that control oxidative stress, superoxide dismutase 2 (SOD2) and isocitrate dehydrogenase 2 (IDH2), are acetylated enzymes and their deacetylation by SIRT3 enhances their enzymatic activities (Fig. 4) (Qiu et al. 2010; Tao et al. 2010).

In addition to its effect on life span, CR also slows the progression of age-related hearing loss, a common age-related disorder associated with oxidative stress. Importantly, mice lacking SIRT3 show no protective effect of CR on age-related hearing loss (Someya et al. 2010). This observation suggests that SIRT3 might be an important mediator of other beneficial aspects of $\mathrm{CR}$, including increased life span. Thus, SIRT3 plays an essential role in mediating at least some of the beneficial effects of CR.

\section{SIRT3 EXPRESSION IS DOWN-REGULATED DURING HIGH-FAT FEEDING}

Whereas the previous sections have focused on the role of SIRT3 under conditions characterized by restricted calorie input (fasting and CR), it is important to know that SIRT3 also plays a significant role under conditions of calorie excess. The metabolic syndrome is defined by central obesity, insulin resistance, hyperlipidemia, hyperglycemia, and hypertension (Reaven 1988). Prevalence of the metabolic syndrome is rising in the Western world and will lead to future increases in diabetes and cardiovascular disease (Ford et al. 2008). Sedentary lifestyles (Ardern et al. 2004) and high-fat "Western" diets (Feldeisen and Tucker 2007) have been implicated in the increase in metabolic syndrome.

In addition to lifestyle and diet, several genes are implicated in the pathogenesis of metabolic disease, such as those encoding leptin, $\beta$-3-adrenergic receptor, hormone-sensitive lipase, lipoprotein lipase, insulin receptor substrate 1, PC-1, and skeletal muscle glycogen synthase (Zhang et al. 1994; Groop 2000; Poulsen et al. 2001; Pollex and Hegele 2006). In addition to candidate genes, multiple metabolic pathways are also implicated, including aberrant lipogenesis (Roden et al. 1996; Samuel et al. 2004), increased inflammation (Hotamisligil et al. 1993; Uysal et al. 1997), and reduced fatty-acid oxidation (Ji and Friedman 2007, 2008). Identifying the molecular mechanisms underlying the metabolic syndrome has been described as one of the most critical endeavors in modern medicine (Taubes 2009).

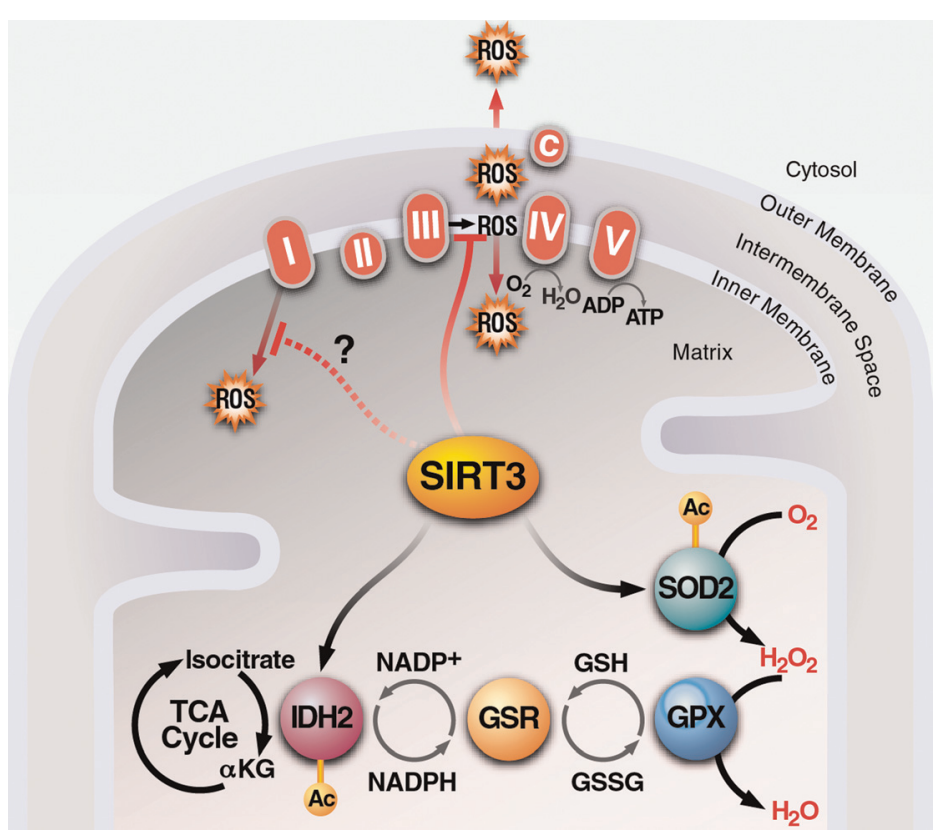

Figure 4. SIRT3 protects against ROS-induced damage. ROS are generated in the mitochondria from the oxidation of metabolic substrates. ROS such as superoxide $\left(\mathrm{O}_{2}\right)$ are converted into hydrogen peroxide $\left(\mathrm{H}_{2} \mathrm{O}_{2}\right)$ by mitochondrial manganese superoxide dismutase (SOD2), which is further converted into water by glutathione peroxidase (GPX). GPX requires reduced glutathione (GSH) for its enzymatic activity, which is regulated by glutathione reductase (GSR) and NADPH. Mitochondrial isocitrate dehydrogenase 2 (IDH2) generates NADPH from NADP ${ }^{+}$. SIRT3 influences this process by deacetylating and activating both SOD2 and IDH2 and thereby regulates oxidative damage in cells. $\alpha \mathrm{KG}, \alpha$-Ketoglutarate; GSSG, oxidized glutathione disulfide. 
We have recently observed that lack of SIRT3 and mitochondrial protein hyperacetylation lead to accelerated development of the metabolic syndrome and its manifestations (Hirschey et al. 2011). WT mice fed a high-fat diet (HFD) develop obesity, hyperlipidemia, type 2 diabetes mellitus, insulin resistance, and nonalcoholic steatohepatitis (Surwit et al. 1995; Rossmeisl et al. 2003; Collins et al. 2004; Petro et al. 2004). We find that the development of each of these consequences of HFD feeding is significantly accelerated in mice lacking SIRT3 (Hirschey et al. 2011). In addition, we also find that mice lacking SIRT3 show dramatically enhanced levels of proinflammatory cytokines, including interferon- $\gamma$, IL-10, IL-12p70, IL-6, and TNF- $\alpha$, in agreement with the discussed role of SIRT3 in the control of oxidative stress. Interestingly, LCAD deficiency is also associated with accelerated development of insulin resistance and steatohepatitis in mice (Zhang et al. 2007), primarily attributed to lipid accumulation from reduced fatty-acid oxidation (Kurtz et al. 1998). Additionally, ablation of malonyl-CoA decarboxylase (MCD), an enzyme that regulates mitochondrial fatty-acid oxidation, also leads to reduced fatty-acid oxidation and insulin resistance (Koves et al. 2008). Thus, primary lesions in fatty-acid oxidation upon ablation of SIRT3, LCAD, or MCD result in insulin resistance and support a role for mitochondrial lipid oxidation in the maintenance of insulin signaling and metabolic homeostasis (Fig. 5).

We also found that prolonged exposure to HFD feeding in WT mice results in a reduction of hepatic SIRT3 expression. Similar observations were previously reported by Bao et al. (2010). Whereas acute HFD feeding leads to an increase in SIRT3 protein expression, chronic HFD feeding (13 wk) suppresses SIRT3 protein expression and induces global mitochondrial protein hyperacetylation, LCAD hyperacetylation, and reduced LCAD activity. The reduction in LCAD activity is phenocopied in SIRT3KO mice. The suppression of SIRT3 occurs at the transcriptional level and is primarily driven by the HFD-induced suppression of PGC-1 $\alpha$ (Crunkhorn et al. 2007; Li et al. 2007), a major regulator of SIRT3 expression (Kong et al. 2010; JY Huang and E Verdin, unpubl.). Overexpression of exogenous PGC- $1 \alpha$ was sufficient to rescue the loss of SIRT3 in HFD-fed mice. Fatty-acid oxidation is also suppressed by HFD feeding, although the molecular mechanism is incompletely understood (Ji and Friedman 2007, 2008). Our observations support the model that PGC-1 $\alpha$ and SIRT3 down-regulation and mitochondrial protein hyperacetylation play a critical role in this process.

Finally, we have studied the possible role of human polymorphisms in the SIRT3 gene in the development of the metabolic syndrome in humans. Because singlenucleotide polymorphisms (SNPs) in SIRT3 have not been identified in large-scale genome-wide association studies in obesity (Lindgren et al. 2009; Heid et al. 2010; Speliotes et al. 2010), diabetes (Prokopenko et al. 2009; Dupuis et al. 2010), or cholesterol and lipid metabolism (Musunuru et al. 2010; Teslovich et al. 2010), we focused our initial analysis on a population characterized by fatty liver disease (the NASH-CRN), reasoning that such a population should show increased frequency of the metabolic syndrome and might therefore be enriched in patients carrying predisposing SIRT3 alleles. We found that patients meeting the criteria for metabolic syndrome were more likely to carry the SIRT3 rs11246020 "A" minor allele. In a follow-up study of $\sim 8000$ Finnish men focusing specifically on rs11246020, we sought to validate this SNP association with the metabolic syndrome (Stancáková et al. 2009). We observed a significant correlation between the frequency of this allele and a metabolic syndrome diagnosis, supporting the findings in the NASH-CRN study. However, this association was relatively weak (odds ratio, 1.3) and was not observed with all definitions of the metabolic syndrome. Given the heterogeneity of the metabolic syndrome as a clinical entity, it will be important to further validate these observations in larger cohorts of patients and to further determine whether the SIRT3 polymorphism associates more strongly with unique manifestations of the metabolic syndrome rather than with the syndrome as a whole. Remarkably, the SIRT3 rs11246020 polymorphism is present with an exon of SIRT3 and induces a mutation within the catalytic domain of SIRT3 (V208I). Mutation of valine 208 into isoleucine reduces SIRT3 enzyme efficiency, both by increasing the $K_{\mathrm{M}}$ for $\mathrm{NAD}^{+}$and reducing the $V_{\max }$. These data are consistent with the model that reduction in SIRT3 enzymatic activity associated with the SIRT3 rs1 1246020 polymorphism and the consequent V208I mutation play a pathogenic role in humans, as in mice, and increases susceptibility to the metabolic syndrome. Together, these observations highlight the importance of using primary cellular and mouse data to direct human genetic studies and the power of integrating these data to glean insights into the relationships between human SNPs and the underlying biology.

\section{MITOCHONDRIAL PROTEIN ACETYLATION AND METABOLIC REGULATION}

In conclusion, every metabolic pathway contains acetylated proteins in both bacteria and human liver (Wang et al. 2010; Zhao et al. 2010) and acetylation has emerged as an important regulatory posttranslational modification in mitochondria (Hirschey et al. 2010). Changes in metabolic status, including CR (Schwer et al. 2009) and HFD feeding (Hirschey et al. 2011), lead to changes in mitochondria protein acetylation. Interestingly, fatty-acid oxidation is elevated during both CR (Koubova and Guarente 2003) and HFD feeding (Kim et al. 2004). Because increased fatty-acid oxidation leads to higher intramitochondrial acetyl-CoA levels, mitochondrial protein acetylation increases via either nonenzymatic acetylation of mitochondrial proteins or the activity of a yet unidentified mitochondrial acetyltransferases (MAT) (Fig. 6). This model, however, brings a significant conundrum: How could two feeding regimens (CR and HFD) that induce such different outcomes (insulin resistance vs. insulin sensitivity; increased vs. decreased life span) be 


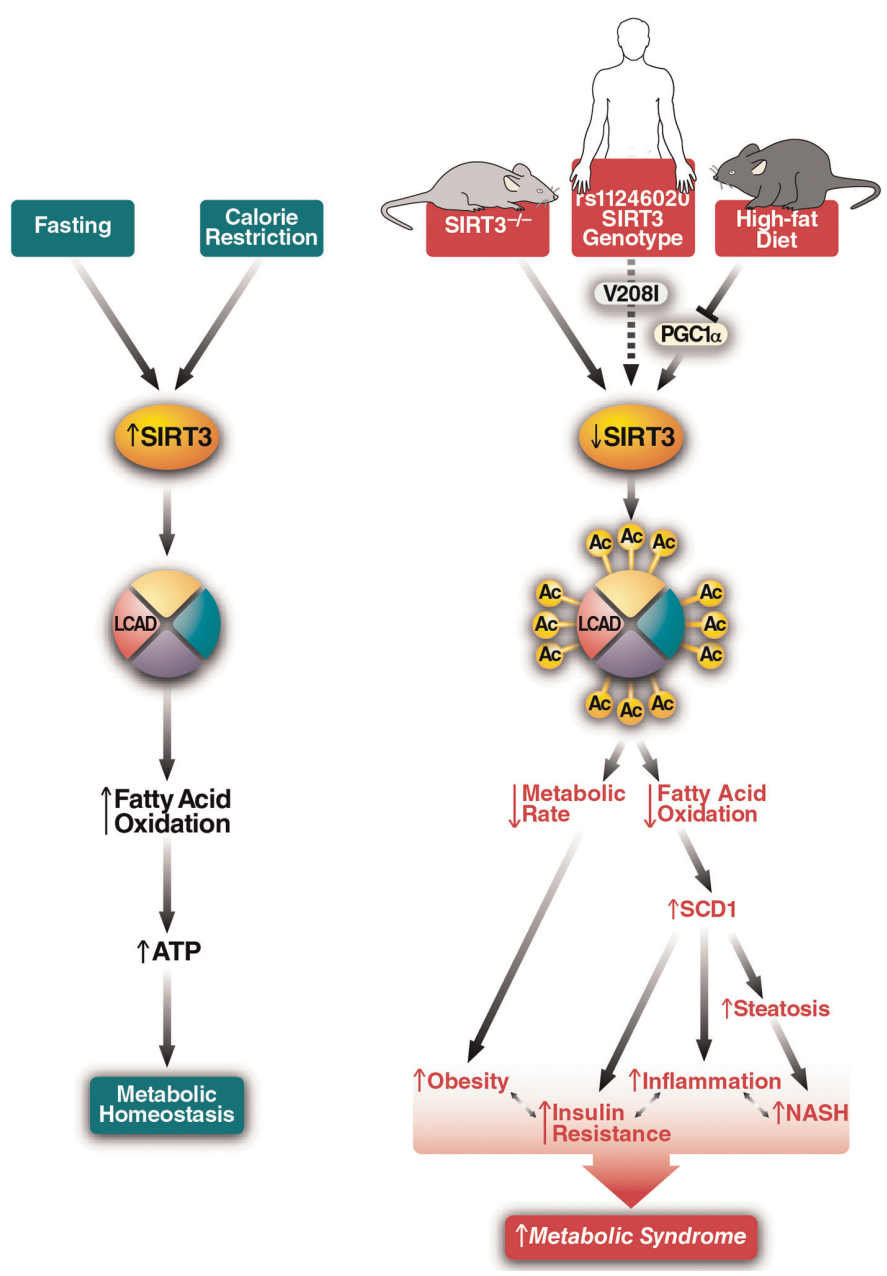

Figure 5. Role of mitochondrial protein acetylation and SIRT3 in the pathogenesis of the metabolic syndrome. SIRT3 deacetylates several mitochondrial proteins and increases fatty-acid oxidation and ATP production. In SIRT3KO mice or mice fed a high-fat diet, specific mitochondrial proteins become hyperacetylated, resulting in less energy expenditure and lower fatty-acid oxidation levels, which both contribute to insulin resistance, obesity, and increased inflammation. Similarly, humans with a unique singlenucleotide polymorphism in the SIRT3 gene have reduced SIRT3 enzymatic efficiency and could have increased risk of developing the metabolic syndrome.

characterized by enhanced mitochondrial protein acetylation? We propose that changes in SIRT3 protein expression represent the key difference between these two conditions (Fig. 5). As discussed above, SIRT3 expression is highly sensitive to the overall metabolic status of the cell, where caloric deprivation (e.g., fasting, CR, exercise) results in increased SIRT3 expression (Shi et al. 2005; Lanza et al. 2008; Palacios et al. 2009; Hirschey et al. 2010), whereas caloric excess (e.g., HFD feeding) results in reduced SIRT3 expression (Palacios et al. 2009; Hirschey et al. 2011). Additionally, SIRT3 protein expression is sensitive to aging, where reduced protein expression is observed in aged human populations (Lanza et al. 2008) as well as in aged mice (M Hirschey and $\mathrm{E}$ Verdin, unpubl.). Based on our study of individual targets of SIRT3, we also note that global mitochondrial protein acetylation does not always correlate with the acetylation status of individually relevant targets. For example, the specific SIRT3 target LCAD becomes deacetylated during fasting in WT mice when global mitochondrial protein acetylation is increased and SIRT3 expression is also high (Hirschey et al. 2010). However, LCAD becomes hyperacetylated during HFD feeding in WT mice when global mitochondrial protein acetylation is high but SIRT3 expression is low (Hirschey et al. 2011). Thus, we propose as a working model that SIRT3 plays a crucial role in determining the fate of mitochondrial protein acetylation and whether acetylation results in an overall beneficial or detrimental metabolic effect (Fig. 5).

\section{FUTURE QUESTIONS}

Further work will be required to identify how protein acetylation and deacetylation by SIRT3 are balanced in the mitochondria. Because histone acetyltransferases regulate protein acetylation in the nucleus, a MAT could acetylate proteins in the mitochondria (Fig. 6). Acetyl-CoA levels could also directly regulate protein acetylation via 


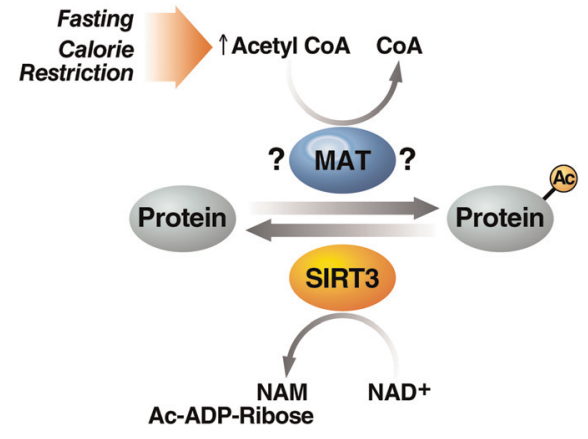

Figure 6. Regulation of mitochondrial protein acetylation. Acetyl-CoA levels rise during fasting and calorie restriction. HFD feeding increases fatty-acid oxidation and could also lead to increased acetyl-CoA levels. Increased mitochondrial acetylCoA levels probably increase mitochondrial protein acetylation, either nonenzymatically or via the activity of a yet to be identified mitochondrial acetyltransferase (MAT). Hyperacetylation of mitochondrial proteins inhibits fatty-acid oxidation, at least in part, via inhibition of LCAD activity. This process could function as a negative-feedback inhibition loop suppressing fattyacid oxidation when acetyl-CoA levels become elevated. Under prolonged fasting conditions or under CR, however, SIRT3 expression is activated and deacetylates LCAD and other enzymes in the fatty-acid oxidation pathway. This activity suppresses the negative-feedback loop imposed by protein hyperacetylation and allows fatty-acid oxidation to proceed in the presence of elevated acetyl-CoA levels. Aberrant SIRT3 downregulation under high-fat feeding conditions is associated with mitochondrial protein hyperacetylation, accumulation of fattyacid oxidation intermediary products, and the induction of insulin resistance.

nonenzymatic acetylation. Interestingly, increased fattyacid oxidation during calorie restriction or fasting leads to increased mitochondrial acetyl-CoA concentrations and therefore increased mitochondrial protein acetylation; however, SIRT3 expression and activity are induced under the same conditions and lead to a compensatory decrease in mitochondrial protein acetylation. HFD feeding is also associated with increased fatty-acid oxidation and increased mitochondrial acetyl-CoA levels, and SIRT3 expression is induced early after initiation of high-fat feeding (Hirschey et al. 2011). However, in contrast to CR or fasting-induced SIRT3 expression, chronic HFD feeding suppresses SIRT3 expression, increases mitochondrial protein acetylation, and ultimately reduces fatty-acid oxidation.

We conclude that mitochondrial protein acetylation is a critical posttranslational modification, whose regulation by SIRT3 is necessary to maintain metabolic health in mice and humans. Future studies will examine the therapeutic potential of manipulating SIRT3 expression or activity in ameliorating manifestations of the metabolic syndrome.

\section{ACKNOWLEDGMENTS}

We thank John Carroll for figure preparation and Gary Howard for editorial review. Funding for this work was supported in part by a UCSF Postdoctoral Research
Fellowship Award from the Sandler Foundation (M.D.H and B.S.), a Postdoctoral Fellowship from the Hillblom Foundation (J.-Y.H), a Senior Scholarship in Aging from the Ellison Medical Foundation (E.V.), the UCSF Liver Center though the NIDDK (P30 DK026743; E.V.), an R24 grant from NIDDK (DK085610; E.V.), and institutional support from the J. David Gladstone Institutes (E.V.).

\section{REFERENCES}

Ahn BH, Kim HS, Song S, Lee IH, Liu J, Vassilopoulos A, Deng CX, Finkel T. 2008. A role for the mitochondrial deacetylase Sirt3 in regulating energy homeostasis. Proc Natl Acad Sci 105: $14447-14452$.

Ahuja N, Schwer B, Carobbio S, Waltregny D, North BJ, Castronovo V, Maechler P, Verdin E. 2007. Regulation of insulin secretion by SIRT4, a mitochondrial ADP-ribosyltransferase. J Biol Chem 282: 33583-33592.

Anderson RM, Bitterman KJ, Wood JG, Medvedik O, Sinclair DA. 2003. Nicotinamide and PNC1 govern lifespan extension by calorie restriction in Saccharomyces cerevisiae. Nature 423: $181-185$.

Ardern CI, Katzmarzyk PT, Janssen I, Leon AS, Wilmore JH, Skinner JS, Rao DC, Després JP, Rankinen T, Bouchard C. 2004. Race and sex similarities in exercise-induced changes in blood lipids and fatness. Med Sci Sports Exerc 36: $1610-1615$.

Bao J, Scott I, Lu Z, Pang L, Dimond CC, Gius D, Sack MN. 2010. SIRT3 is regulated by nutrient excess and modulates hepatic susceptibility to lipotoxicity. Free Radic Biol Med 49: $1230-1237$.

Befroy D, Petersen K, Dufour S, Mason G, de Graff R, Rothman DL, Shulman GI. 2007. Impaired mitochondrial substrate oxidation in muscle of insulin-resistant offspring of type 2 diabetic patients. Diabetes 56: 1376-1381.

Bitterman KJ, Anderson RM, Cohen HY, Latorre-Esteves M, Sinclair DA. 2002. Inhibition of silencing and accelerated aging by nicotinamide, a putative negative regulator of yeast sir2 and human SIRT1. J Biol Chem 277: 45099-45107.

Blander G, Guarente L. 2004. The Sir2 family of protein deacetylases. Annu Rev Biochem 73: 417-435.

Bordone L, Guarente L. 2005. Calorie restriction, SIRT1 and metabolism: Understanding longevity. Nat Rev Mol Cell Biol 6: 298-305.

Buckley BM, Williamson DH. 1977. Origins of blood acetate in the rat. Biochem J 166: 539-545.

Chen IY, Lypowy J, Pain J, Sayed D, Grinberg S, Alcendor RR, Sadoshima J, Abdellatif M. 2006. Histone H2A.z is essential for cardiac myocyte hypertrophy but opposed by silent information regulator $2 \alpha$. J Biol Chem 281: 19369-19377.

Civitarese A, Ukropcova B, Carling S, Hulver M, DeFronzo RA, Mandarino L, Ravussin E, Smith SR. 2006. Role of adiponectin in human skeletal muscle bioenergetics. Cell Metab 4: $75-87$.

Civitarese AE, Maclean PS, Carling S, Kerr-Bayles L, Mcmillan RP, Pierce A, Becker TC, Moro C, Finlayson J, Lefort N, et al. 2010. Regulation of skeletal muscle oxidative capacity and insulin signaling by the mitochondrial rhomboid protease PARL. Cell Metab 11: 412-426.

Collins S, Martin TL, Surwit RS, Robidoux J. 2004 . Genetic vulnerability to diet-induced obesity in the C57BL/6J mouse: Physiological and molecular characteristics. Physiol Behav 81: $243-248$.

Cooper HM, Huang J-Y, Verdin E, Spelbrink JN. 2009. A new splice variant of the mouse SIRT3 gene encodes the mitochondrial precursor protein. PLOS ONE 4: e4986.

Crunkhorn S, Dearie F, Mantzoros C, Gami H, da Silva WS, Espinoza D, Faucette R, Barry K, Bianco AC, Patti ME. 2007. Peroxisome proliferator activator receptor gamma 
coactivator-1 expression is reduced in obesity: Potential pathogenic role of saturated fatty acids and p38 mitogen-activated protein kinase activation. $J$ Biol Chem 282: 15439-15450.

Denu JM. 2005. The Sir2 family of protein deacetylases. Curr Opin Chem Biol 9: 431-440.

Dupuis J, Langenberg C, Prokopenko I, Saxena R, Soranzo N, Jackson AU, Wheeler E, Glazer NL, Bouatia-Naji N, Gloyn AL, et al. 2010. New genetic loci implicated in fasting glucose homeostasis and their impact on type 2 diabetes risk. Nat Genet 42: 105-116.

Feldeisen SE, Tucker KL. 2007. Nutritional strategies in the prevention and treatment of metabolic syndrome. Appl Physiol Nutr Metab 32: 46-60.

Ford ES, Li C, Zhao G, Pearson WS, Mokdad AH. 2008. Prevalence of the metabolic syndrome among U.S. adolescents using the definition from the International Diabetes Federation. Diabetes Care 31: 587-589.

Frye RA. 1999. Characterization of five human cDNAs with homology to the yeast SIR2 gene: Sir2-like proteins (sirtuins) metabolize NAD and may have protein ADP-ribosyltransferase activity. Biochem Biophys Res Commun 260: $273-279$.

Frye R. 2000. Phylogenetic classification of prokaryotic and eukaryotic Sir2-like proteins. Biochem Biophys Res Commun 273: $793-798$.

Fujino T, Kondo J, Ishikawa M, Morikawa K, Yamamoto TT. 2001. Acetyl-CoA synthetase 2, a mitochondrial matrix enzyme involved in the oxidation of acetate. $J$ Biol Chem 276: $11420-11426$

Glozak MA, Sengupta N, Zhang X, Seto E. 2005. Acetylation and deacetylation of non-histone proteins. Gene 363: 15-23.

Groop L. 2000. Genetics of the metabolic syndrome. Br J Nutr 83: S39-S48.

Hagopian K, Ramsey JJ, Weindruch R. 2003a. Caloric restriction increases gluconeogenic and transaminase enzyme activities in mouse liver. Exp Gerontol 38: 267-278.

Hagopian K, Ramsey JJ, Weindruch R. 2003b. Influence of age and caloric restriction on liver glycolytic enzyme activities and metabolite concentrations in mice. Exp Gerontol 38: $253-266$.

Haigis MC, Sinclair DA. 2010. Mammalian sirtuins: Biological insights and disease relevance. Annu Rev Pathol: Mech Dis 5: 253-295.

Haigis MC, Mostoslavsky R, Haigis KM, Fahie K, Christodoulou DC, Murphy AJ, Valenzuela DM, Yancopoulos GD, Karow M, Blander G, et al. 2006. SIRT4 inhibits glutamate dehydrogenase and opposes the effects of calorie restriction in pancreatic $\beta$ cells. Cell 126: $941-954$.

Hallows W, Lee S, Denu J. 2006. Sirtuins deacetylate and activate mammalian acetyl-CoA synthetases. Proc Natl Acad Sci 103: $10230-10235$

Heid IM, Jackson AU, Randall JC, Winkler TW, Qi L, Steinthorsdottir V, Thorleifsson G, Zillikens MC, Speliotes EK, Mägi R, et al. 2010. Meta-analysis identifies 13 new loci associated with waist-hip ratio and reveals sexual dimorphism in the genetic basis of fat distribution. Nat Genet 42: 949-960.

Hirschey M, Shimazu T, Goetzman E, Jing E, Schwer B, Lombard D, Grueter C, Harris C, Biddinger S, Ilkayeva O, et al. 2010. SIRT3 regulates mitochondrial fatty acid oxidation via reversible enzyme deacetylation. Nature 464: 121-125.

Hirschey M, Aouizerat B, Jing E, Shimazu T, Grueter C, Collins A, Stevens R, Lam M, Muehlbauer M, Schwer B, et al. 2011. SIRT3 deficiency and mitochondrial protein hyperacetylation accelerate the development of the metabolic syndrome. Mol Cell doi: 10.1016/j.molcel.2011.07.019.

Hotamisligil GS, Shargill NS, Spiegelman BM. 1993. Adipose expression of tumor necrosis factor- $\alpha$ : Direct role in obesitylinked insulin resistance. Science 259: 87-91.

Imai S, Armstrong CM, Kaeberlein M, Guarente L. 2000. Transcriptional silencing and longevity protein Sir2 is an NADdependent histone deacetylase. Nature 403: 795-800.
Ji H, Friedman MI. 2007. Reduced capacity for fatty acid oxidation in rats with inherited susceptibility to diet-induced obesity. Metab Clin Exp 56: 1124-1130.

Ji H, Friedman M. 2008. Reduced hepatocyte fatty acid oxidation in outbred rats prescreened for susceptibility to diet-induced obesity. Int J Obes (Lond) 32: 1331-1334.

Jin L, Galonek H, Israelian K, Choy W, Morrison M, Xia Y, Wang X, Xu Y, Yang Y, Smith JJ, et al. 2009. Biochemical characterization, localization, and tissue distribution of the longer form of mouse SIRT3. Protein Sci 18: 514-525.

Kawahara TLA, Michishita E, Adler AS, Damian M, Berber E, Lin M, McCord RA, Ongaigui KCL, Boxer LD, Chang HY, Chua KF. 2009. SIRT6 links histone H3 lysine 9 deacetylation to NF-кB-dependent gene expression and organismal life span. Cell 136: 62-74.

Kelley D, He J, Menshikova E, Ritov V. 2002. Dysfunction of mitochondria in human skeletal muscle in type 2 diabetes. Diabetes 51: 2944-2950.

Kim S, Sohn I, Ahn J-I, Lee K-H, Lee YS, Lee YS. 2004. Hepatic gene expression profiles in a long-term high-fat diet-induced obesity mouse model. Gene 340: 99-109.

Kim SC, Sprung R, Chen Y, Xu Y, Ball H, Pei J, Cheng T, Kho Y, Xiao H, Xiao L, et al. 2006. Substrate and functional diversity of lysine acetylation revealed by a proteomics survey. Mol Cell 23: 607-618.

Kong X, Wang R, Xue Y, Liu X, Zhang H, Chen Y, Fang F, Chang Y. 2010. Sirtuin 3, a new target of PGC-1 $\alpha$, plays an important role in the suppression of ROS and mitochondrial biogenesis. PLOS ONE 5: e11707.

Koubova J, Guarente L. 2003. How does calorie restriction work? Genes Dev 17: 313-321.

Koves TR, Ussher JR, Noland RC, Slentz D, Mosedale M, Ilkayeva O, Bain J, Stevens R, Dyck JRB, Newgard CB, et al. 2008. Mitochondrial overload and incomplete fatty acid oxidation contribute to skeletal muscle insulin resistance. Cell Metab 7: 45-56.

Kurtz DM, Rinaldo P, Rhead WJ, Tian L, Millington DS, Vockley J, Hamm DA, Brix AE, Lindsey JR, Pinkert CA, et al. 1998. Targeted disruption of mouse long-chain acyl-CoA dehydrogenase gene reveals crucial roles for fatty acid oxidation. Proc Natl Acad Sci 95: 15592-15597.

Landry J, Slama JT, Sternglanz R. 2000. Role of NAD(+) in the deacetylase activity of the SIR2-like proteins. Biochem Biophys Res Commun 278: 685-690.

Lanza IR, Short DK, Short KR, Raghavakaimal S, Basu R, Joyner MJ, McConnell JP, Nair KS. 2008. Endurance exercise as a countermeasure for aging. Diabetes 57: 2933-2942.

Li X, Monks B, Ge Q, Birnbaum MJ. 2007. Akt/PKB regulates hepatic metabolism by directly inhibiting PGC-1 $\alpha$ transcription coactivator. Nature 447: 1012-1016.

Lin SJ, Defossez PA, Guarente L. 2000. Requirement of NAD and SIR2 for life-span extension by calorie restriction in $\mathrm{Sac}$ charomyces cerevisiae. Science 289: 2126-2128.

Lin SJ, Kaeberlein M, Andalis AA, Sturtz LA, Defossez PA, Culotta VC, Fink GR, Guarente L. 2002. Calorie restriction extends Saccharomyces cerevisiae lifespan by increasing respiration. Nature 418: 344-348.

Lin J, Wu PH, Tarr PT, Lindenberg KS, St-Pierre J, Zhang CY, Mootha VK, Jager S, Vianna CR, Reznick RM, et al. 2004. Defects in adaptive energy metabolism with CNS-linked hyperactivity in PGC-1 $\alpha$ null mice. Cell 119: 121-135.

Lindgren CM, Heid IM, Randall JC, Lamina C, Steinthorsdottir V, Qi L, Speliotes EK, Thorleifsson G, Willer CJ, Herrera BM, et al. 2009. Genome-wide association scan meta-analysis identifies three loci influencing adiposity and fat distribution. PLoS Genet 5: e1000508.

Lombard DB, Alt FW, Cheng HL, Bunkenborg J, Streeper RS, Mostoslavsky R, Kim J, Yancopoulos G, Valenzuela D, Murphy A, et al. 2007. Mammalian Sir2 homolog SIRT3 regulates global mitochondrial lysine acetylation. Mol Cell Biol 27: 8807-8814.

Masoro EJ. 2005. Overview of caloric restriction and ageing. Mech Ageing Dev 126: 913-922. 
Matsunaga T, Isohashi F, Nakanishi Y, Sakamoto Y. 1985. Physiological changes in the activities of extramitochondrial acetyl-CoA hydrolase in the liver of rats under various metabolic conditions. Eur J Biochem 152: 331-336.

McCay C, Cromwell M, Maynard L. 1935. The effect of retarded growth upon the length of life span and upon the ultimate body size. J Nutr 10: 63-79.

Michishita E, Park JY, Burneskis JM, Barrett JC, Horikawa I. 2005. Evolutionarily conserved and nonconserved cellular localizations and functions of human SIRT proteins. Mol Biol Cell 16: 4623-4635.

Musunuru K, Strong A, Frank-Kamenetsky M, Lee NE, Ahfeldt T, Sachs KV, Li X, Li H, Kuperwasser N, Ruda VM, et al. 2010. From noncoding variant to phenotype via SORT1 at the 1p13 cholesterol locus. Nature 466: 714-719.

Nakagawa T, Lomb DJ, Haigis MC, Guarente L. 2009. SIRT5 deacetylates carbamoyl phosphate synthetase 1 and regulates the urea cycle. Cell 137: 560-570.

North BJ, Verdin E. 2004. Sirtuins: Sir2-related NADdependent protein deacetylases. Genome Biol 5: 224.

Onyango P, Celic I, McCaffery JM, Boeke JD, Feinberg AP. 2002. SIRT3, a human SIR2 homologue, is an NADdependent deacetylase localized to mitochondria. Proc Natl Acad Sci 99: 13653-13658.

Palacios OM, Carmona JJ, Michan S, Chen KY, Manabe Y, Ward JL, Goodyear LJ, Tong Q. 2009. Diet and exercise signals regulate SIRT3 and activate AMPK and PGC-1 $\alpha$ in skeletal muscle. Aging 1: 771-783.

Patti M-E, Butte AJ, Crunkhorn S, Cusi K, Berria R, Kashyap S, Miyazaki Y, Kohane I, Costello M, Saccone R, et al. 2003. Coordinated reduction of genes of oxidative metabolism in humans with insulin resistance and diabetes: Potential role of PGC1 and NRF1. Proc Natl Acad Sci 100: 8466-8471.

Petersen KF, Dufour S, Befroy D, Garcia R, Shulman GI. 2004. Impaired mitochondrial activity in the insulin-resistant offspring of patients with type 2 diabetes. $N$ Engl J Med 350: $664-671$.

Petersen KF, Dufour S, Shulman GI. 2005. Decreased insulinstimulated ATP synthesis and phosphate transport in muscle of insulin-resistant offspring of type 2 diabetic parents. PLoS Med 2: e233.

Petro AE, Cotter J, Cooper DA, Peters JC, Surwit SJ, Surwit RS. 2004. Fat, carbohydrate, and calories in the development of diabetes and obesity in the C57BL/6J mouse. Metabolism 53: $454-457$.

Pollex RL, Hegele RA. 2006. Genetic determinants of the metabolic syndrome. Nat Clin Pract Cardiovasc Med 3: 482-489.

Poulsen P, Vaag A, Kyvik K, Beck-Nielsen H. 2001. Genetic versus environmental aetiology of the metabolic syndrome among male and female twins. Diabetologia 44: 537-543.

Prokopenko I, Langenberg C, Florez JC, Saxena R, Soranzo N, Thorleifsson G, Loos RJF, Manning AK, Jackson AU, Aulchenko Y, et al. 2009. Variants in MTNR1B influence fasting glucose levels. Nat Genet 41: 77-81.

Qiu X, Brown K, Hirschey MD, Verdin E, Chen D. 2010. Calorie restriction reduces oxidative stress by SIRT3-mediated SOD2 activation. Cell Metab 12: 662-667.

Reaven GM. 1988. Banting lecture 1988. Role of insulin resistance in human disease. Diabetes 37: 1595-1607.

Reinberg D. 2011. Nuclear function of SirT3. Cold Spring Harb Symp Quant Biol doi: 10.1101/sqb.2011.76.a010744 (in press).

Roden M, Price TB, Perseghin G, Petersen KF, Rothman DL, Cline GW, Shulman GI. 1996. Mechanism of free fatty acid-induced insulin resistance in humans. $J$ Clin Invest 97: 2859-2865.

Rossmeisl M, Rim JS, Koza LP. 2003. Variation in type 2 diabetes-related traits in mouse strains susceptible to diet-induced obesity. Diabetes 52: 1958-1966.

Sakakibara I, Fujino T, Ishii M, Tanaka T, Shimosawa T, Miura S, Zhang W, Tokutake Y, Yamamoto J, Awano M, et al. 2009. Fasting-induced hypothermia and reduced energy production in mice lacking acetyl-CoA synthetase 2. Cell Metab 9: $191-202$.
Samuel VT, Liu ZX, Qu X, Elder BD, Bilz S, Befroy D, Romanelli AJ, Shulman GI. 2004. Mechanism of hepatic insulin resistance in non-alcoholic fatty liver disease. J Biol Chem 279: $32345-32353$.

Sauve AA, Wolberger C, Schramm VL, Boeke JD. 2006. The biochemistry of sirtuins. Annu Rev Biochem 75: 435-465.

Scher MB, Vaquero A, Reinberg D. 2007. SirT3 is a nuclear $\mathrm{NAD}^{+}$-dependent histone deacetylase that translocates to the mitochondria upon cellular stress. Genes Dev 21: 920928.

Schlicker C, Gertz M, Papatheodorou P, Kachholz B, Becker CF, Steegborn C. 2008. Substrates and regulation mechanisms for the human mitochondrial sirtuins Sirt3 and Sirt5. J Mol Biol 382: 790-801.

Schwer B, Verdin E. 2008. Conserved metabolic regulatory functions of sirtuins. Cell Metab 7: 104-112.

Schwer B, North BJ, Frye RA, Ott M, Verdin E. 2002. The human silent information regulator (Sir)2 homologue hSIRT3 is a mitochondrial nicotinamide adenine dinucleotide-dependent deacetylase. J Cell Biol 158: 647-657.

Schwer B, Bunkenborg J, Verdin RO, Andersen JS, Verdin E. 2006. Reversible lysine acetylation controls the activity of the mitochondrial enzyme acetyl-CoA synthetase 2. Proc Natl Acad Sci 103: 10224-10229.

Schwer B, Eckersdorff M, Li Y, Silva J, Fermin D, Kurtev M, Giallourakis C, Comb M, Alt F, Lombard D. 2009. Calorie restriction alters mitochondrial protein acetylation. Aging Cell 8: 604-606.

Seufert CD, Graf M, Janson G, Kuhn A, Soling HD. 1974. Formation of free acetate by isolated perfused livers from normal, starved and diabetic rats. Biochem Biophys Res Commun 57: 901-909.

Shi T, Wang F, Stieren E, Tong Q. 2005. SIRT3, a mitochondrial sirtuin deacetylase, regulates mitochondrial function and thermogenesis in brown adipocytes. J Biol Chem 280: $13560-13567$.

Shimazu T, Hirschey M, Hua L, Dittenhafer-Reed KE, Schwer B, Lombard D, Li Y, Bunkenborg J, Alt FW, Denu JM, et al. 2010. SIRT3 deacetylates mitochondrial 3-hydroxy-3methylglutaryl CoA synthase 2, increases its enzymatic activity and regulates ketone body production. Cell Metab 12: $654-661$.

Smith JS, Brachmann CB, Celic I, Kenna MA, Muhammad S, Starai VJ, Avalos JL, Escalante-Semerena JC, Grubmeyer C, Wolberger C, Boeke JD. 2000. A phylogenetically conserved $\mathrm{NAD}^{+}$-dependent protein deacetylase activity in the Sir2 protein family. Proc Natl Acad Sci 97: 6658-6663.

Someya S, Yu W, Hallows WC, Xu J, Vann JM, Leeuwenburgh C, Tanokura M, Denu JM, Prolla TA. 2010. Sirt3 mediates reduction of oxidative damage and prevention of agerelated hearing loss under caloric restriction. Cell 143: $802-812$.

Sone H, Shimano H, Sakakura Y, Inoue N, Amemiya-Kudo M, Yahagi N, Osawa M, Suzuki H, Yokoo T, Takahashi A, et al. 2002. Acetyl-coenzyme A synthetase is a lipogenic enzyme controlled by SREBP-1 and energy status. Am J Physiol 282: E222-E230.

Speliotes EK, Willer CJ, Berndt SI, Monda KL, Thorleifsson G, Jackson AU, Allen HL, Lindgren CM, Luan Ja Mägi R, Randall JC, et al. 2010. Association analyses of 249,796 individuals reveal 18 new loci associated with body mass index. Nat Genet 42: 937-948.

Stancáková A, Javorský M, Kuulasmaa T, Haffner SM, Kuusisto J, Laakso M. 2009. Changes in insulin sensitivity and insulin release in relation to glycemia and glucose tolerance in 6,414 Finnish men. Diabetes 58: 1212-1221.

Starai VJ, Celic I, Cole RN, Boeke JD, Escalante-Semerena JC. 2002. Sir2-dependent activation of acetyl-CoA synthetase by deacetylation of active lysine. Science 298: 2390-2392.

Surwit RS, Feinglos MN, Rodin J, Sutherland A, Petro AE, Opara EC, Kuhn CM, Rebuffe-Scrive M. 1995. Differential effects of fat and sucrose on the development of obesity and 
diabetes in $\mathrm{C} 57 \mathrm{BL} / 6 \mathrm{~J}$ and $\mathrm{A} / \mathrm{J}$ mice. Metabolism 44: 645-651.

Tanno M, Sakamoto J, Miura T, Shimamoto K, Horio Y. 2006. Nucleocytoplasmic shuttling of the $\mathrm{NAD}^{+}$-dependent histone deacetylase SIRT1. J Biol Chem 282: 6823-6832.

Tao R, Coleman MC, Pennington JD, Ozden O, Park S-H, Jiang H, Kim H-S, Flynn CR, Hill S, Hayes McDonald W, et al. 2010. Sirt3-mediated deacetylation of evolutionarily conserved lysine 122 regulates MnSOD activity in response to stress. Mol Cell 40: 893-904.

Taubes G. 2009. Insulin resistance. Prosperity's plague. Science 325: $256-260$.

Teslovich TM, Musunuru K, Smith AV, Edmondson AC, Stylianou IM, Koseki M, Pirruccello JP, Ripatti S, Chasman DI, Willer CJ, et al. 2010. Biological, clinical and population relevance of 95 loci for blood lipids. Nature 466: 707-713.

Ukropcova B, Sereda O, de Jonge L, Bogacka I, Nguyen T, Xie H, Bray GA, Smith SR. 2007. Family history of diabetes links impaired substrate switching and reduced mitochondrial content in skeletal muscle. Diabetes 56: 720-727.

Uysal KT, Wiesbrock SM, Marino MW, Hotamisligil GS. 1997. Protection from obesity-induced insulin resistance in mice lacking TNF- $\alpha$ function. Nature 389: 610-614.
Verdin E, Dequiedt F, Fischle W, Frye R, Marshall B, North B. 2004. Measurement of mammalian histone deacetylase activity. Meth Enzymol 377: 180-196.

Wallace DC. 2005. A mitochondrial paradigm of metabolic and degenerative diseases, aging, and cancer: A dawn for evolutionary medicine. Annu Rev Genet 39: 359-407.

Wang Q, Zhang Y, Yang C, Xiong H, Lin Y, Yao J, Li H, Xie L, Zhao W, Yao Y, et al. 2010. Acetylation of metabolic enzymes coordinates carbon source utilization and metabolic flux. Science 327: 1004-1007.

Yamashita H, Kaneyuki T, Tagawa K. 2001. Production of acetate in the liver and its utilization in peripheral tissues. Biochim Biophys Acta 1532: 79-87.

Zhang Y, Proenca R, Maffei M, Barone M, Leopold L, Friedman JM. 1994. Positional cloning of the mouse obese gene and its human homologue. Nature 372: 425-432.

Zhang D, Liu ZX, Choi CS, Tian L, Kibbey R, Dong J, Cline GW, Wood PA, Shulman GI. 2007. Mitochondrial dysfunction due to long-chain Acyl-CoA dehydrogenase deficiency causes hepatic steatosis and hepatic insulin resistance. Proc Natl Acad Sci 104: 17075-17080.

Zhao S, Xu W, Jiang W, Yu W, Lin Y, Zhang T, Yao J, Zhou L, Zeng Y, Li H, et al. 2010. Regulation of cellular metabolism by protein lysine acetylation. Science 327: 1000-1004. 


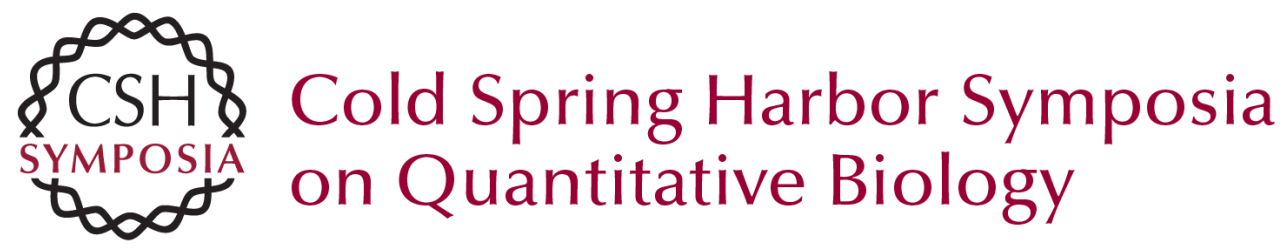

\section{SIRT3 Regulates Mitochondrial Protein Acetylation and Intermediary Metabolism}

M.D. Hirschey, T. Shimazu, J.-Y. Huang, et al.

Cold Spring Harb Symp Quant Biol 2011 76: 267-277 originally published online November 23, 2011

Access the most recent version at doi:10.1101/sqb.2011.76.010850

References This article cites 107 articles, 36 of which can be accessed free at: http://symposium.cshlp.org/content/76/267.full.html\#ref-list-1

\section{License}

Email Alerting Receive free email alerts when new articles cite this article - sign up in Service the box at the top right corner of the article or click here. 